\title{
A Midrange theory of Empowered Holistic Nursing Education: A pedagogy for a student-centered classroom
}

Katie L. Love

Fairfield University, klove@fairfield.edu

Follow this and additional works at: https://digitalcommons.fairfield.edu/nursing-facultypubs

Copyright 2014 Springer

The final publisher PDF has been archived here with permission from the copyright holder.

\section{Peer Reviewed}

\section{Repository Citation}

Love, Katie L., "A Midrange theory of Empowered Holistic Nursing Education: A pedagogy for a studentcentered classroom" (2014). Nursing and Health Studies Faculty Publications. 103.

https://digitalcommons.fairfield.edu/nursing-facultypubs/103

\section{Published Citation}

Love, K. (2014) A Midrange theory of Empowered Holistic Nursing Education: A pedagogy for a student-centered classroom. Creative Nursing, 20 (1), 47-58.

This item has been accepted for inclusion in DigitalCommons@Fairfield by an authorized administrator of DigitalCommons@Fairfield. It is brought to you by DigitalCommons@Fairfield with permission from the rightsholder(s) and is protected by copyright and/or related rights. You are free to use this item in any way that is permitted by the copyright and related rights legislation that applies to your use. For other uses, you need to obtain permission from the rights-holder(s) directly, unless additional rights are indicated by a Creative Commons license in the record and/or on the work itself. For more information, please contact digitalcommons@fairfield.edu. 


\section{A Midrange Theory of Empowered Holistic Nursing Education: A Pedagogy for a Student-Centered Classroom}

Katie Love, PhD, APRN, BC, AHN-C

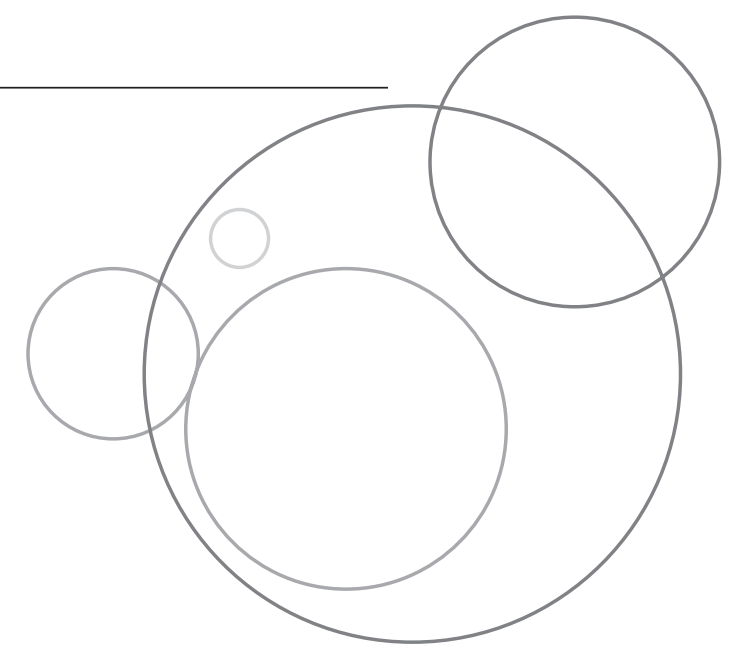

The purpose of this article is to propose Empowered Holistic Nursing Education (EHNE) as a midrange theory-developed through induction, explication, deduction, and retroduction - to help nurse educators teach holistically and create a student-centered classroom, to establish a theoretical basis for a nursing pedagogy reflecting nursing's foundational principles, and to guide future research. The model's 5 core concepts, how to use the model as a pedagogy for practice, and its application to research will be presented. Holistic nursing will be defined, and traditional holistic nursing, holistic pedagogy, and emancipatory pedagogy will each be described.

Keywords: empowered; holistic; nursing pedagogy; cocreating; emancipatory; prior knowledge; contextual; interconnectedness; self-care

E or more than 30 years, authors have appealed for changes in nursing education (Bevis, 1988; Bevis \& Watson, 1989; Moccia, 1988; Spence, 1994), asking for a shift away from behaviorist learning theories and authoritarian power structures in the classroom to an empowered learning culture that focuses on seeking social justice and developing the student as a whole person (Randall, Tate, \& Lougheed, 2007; Yorks \& Sharoff, 2001). Holistic nursing provides the tools to achieve these goals.

This article introduces a midrange theory of EHNE that approaches nursing pedagogy from a holistic perspective. This new theory is based on the premise that students are mind-body-spirit beings who deserve to experience a holistic learning environment, and that this environment extends beyond wellness modalities to include empowered learning in which students create their own knowledge, take responsibility for their education, expect to be treated as whole beings, and gain awareness of socially constructed circumstances that prevent empowerment, growth, and healing (Freire, 1970; Hooks, 1994).

Holistic nursing rejects the compartmentalization of physical care, mental care, and spiritual care. Rather, it focuses on disease prevention, health promotion, therapeutic presence, and interconnectedness. However, holistic principles and practices are not usually brought into the classroom except to teach students how to approach patients holistically or how to integrate complementary and alternative modalities (CAM). The midrange theory of EHNE synthesizes the existing holism literature and

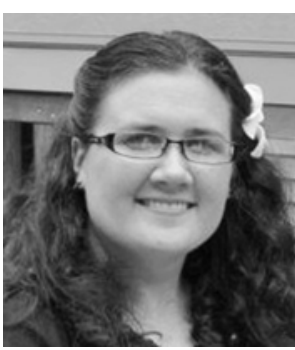

Katie Love, $\mathrm{PhD}$, APRN, BC, AHN-C, is assistant professor and Director of the Multicultural RN-BS program at the University of Saint Joseph in West Hartford, Connecticut. 
Integrating

holism in the

classroom is

crucial because

educational

practices are

guided by the

assumptions

of the nurse

educator, which

can lead to

classrooms

hostile to

multiculturalism

and to biases in

content. expands the concept to include empowerment and emancipatory pedagogies. Integrating holism in the classroom is crucial because educational practices are guided by the assumptions of the nurse educator, which can lead to classrooms hostile to multiculturalism and to biases in content (Bryne, 2001; Love, 2010; Tarca, 2005). The same principles that support patient-centered care can be applied to studentcentered classrooms. Using the EHNE framework, the nurse educator is guided in creating a learning environment consistent with the principles of holistic nursing.

\section{BACKGROUND}

Meleis (2007) supports the development of midrange theories in nursing scholarship at this point because they focus on practice aspects of nursing and reflect the substantiated grand theories of the discipline. A midrange theory generally brings together two or more concepts, and although such theories have limited scope, they improve researchers' ability to test hypotheses, utility, and feasibility. A midrange theory of EHNE allows nurse educators to define and guide nursing pedagogy and to focus research on measurable outcomes, allowing for rigorous, systematic research.

\section{THE DEVELOPMENT OF THE EHNE THEORY}

A midrange theory is strongest when it synthesizes several different approaches (Kolcaba, 2001; Marriner-Tomey \& Alligood, 2006). The EHNE theory was developed using inductive explication, deduction, and retroduction. A concept analysis of interconnectedness, one of the theory's previously undefined components, was explored as a necessary step in developing new conceptual linkages. This concept analysis used a comprehensive method that included art, poetry, multimedia, religious texts, and interdisciplinary literature in addition to nursing research (Love, 2008). Observations from this author's experiences as an educator were also a guiding force in constructing the hypothesis leading to this midrange theory. Sources are cited in the respective relevant sections.

EHNE is a nursing pedagogy, unifying nursing's professional values while allowing space for the individuality of both teacher and student. Additional concepts of holism were originally drawn from spiritual and religious philosophies and Eastern and indigenous health and wellness paradigms. EHNE incorporates the multidisciplinary theories of critical pedagogy, emancipatory education, and holism to form a unique midrange theory that is specific to nursing and will allow for future application and testing.

\section{FINDINGS}

The midrange theory of EHNE contains these propositions.

- People are complex mind-body-spirit beings.

- EHNE provides a multiculturally supportive educational experience.

- Students' growth and development as whole beings and in developing an empowered worldview are ends unto themselves.

- EHNE advocates for social justice and ethical education. 
- Students who experience holism and emancipatory knowing in their education are more likely to use these concepts with their patients.

- Students in an EHNE environment will have better academic success and will be better able to maintain their own wellness.

Using inductive, deductive, and retroductive explorations, the midrange theory of EHNE generated five principles: Prior Knowledge, Contextual TeachingLearning, Interconnectedness, Self-Care, and Meeting Them Where They Are. Figure 1 is a representation of this midrange theory and will be referenced throughout.

\section{HOLISM AND EMANCIPATORY PEDAGOGY}

The American Holistic Nurses Association (AHNA, 1998) defines holistic nursing as "all nursing that has healing the whole person as its goal." A concept analysis of holistic nursing defines it as nursing care that brings harmony to mind-body-spirit, supports personal interconnectedness with others, and fosters spirituality (Tjale \& Bruce, 2007). These authors describe spirituality as manifesting as an empowering transformation and supporting patient-centered and culturally appropriate care. Holistic care must be multicultural and congruent with the values, beliefs, and worldviews of the individual cared for. Multiculturalism must necessarily include advocating for social justice and understanding social constructions of power that prevent mind-body-spirit wellness and healing (Chinn, 2001; Darder, 1991; Leininger \& McFarland, 2002; Randall et al., 2007; Romyn, 2000; Schrieber \& Banister, 2002; Shor, 1992; Van Niekerk, 1999).

Culturally appropriate nursing care demonstrates understanding of how family traditions and worldviews impact health and healing (Tjale \& Bruce, 2007). Culture is specific and contextually bound, combining history, language, and shared experiences (Leininger \& McFarland, 2002). Care that lacks cultural compassion reflects a paternalistic and controlling paradigm (Leininger \& McFarland, 2002; Love, 2009; Tjale \& Bruce, 2007). The first standard of transcultural nursing is social justice, reflecting an understanding that culturally appropriate care fights injustice, advocates, and defines goals and context for the cultural perspective of patients and their community (Transcultural Nursing Society [TNS], 2010). Nurses who have a critical consciousness of diversity, oppression, and health disparities and the injustices that create them are prepared to practice empowered holistic nursing. Likewise, creating an empowered holistic classroom environment that reflects these same concepts will help prepare students to provide holistic care.

Traditional approaches to holistic nursing in education focus on teaching nursing students a holistic approach to patient care and integration of therapeutic modalities. The literature encourages these concepts to be threaded throughout programs (Delaney, 2009; Finn, 1999; Frisch, 2003; Frisch, Dossey, Guzzetta, \& Quinn, 2000; Meyer, 2003). In the traditional approach to holism in nursing education, the focus is not on creating a caring classroom environment, working toward

a critical consciousness of educators and students, or modeling holism through a holistic pedagogy.

Several organizations support a holistic focus in nursing programs. The Commission on Collegiate Nursing Education supports the American Association of Colleges of Nursing's (AACN) Nursing Essentials, a comprehensive document outlining the standards for baccalaureate nursing education (AACN, 2008; Frisch, 2003).

Nurses who

have a critical

consciousness

of diversity,

oppression, and health disparities and the injustices that create them are prepared

to practice

empowered

holistic nursing. 
In a holistic

pedagogy,

courses are

informal and

incorporate

multiple learning

methods

integrating

students' prior

knowledge based

on their clinical

experiences but

also including

their cultural

position, historical

knowledge, and

life experiences.
Nursing Essentials includes a holistic approach in all areas of focus as an important component of nursing practice and encourages nurse educators to guide student nurses in developing a holistic approach to patient care (AACN, 2008). The document states that the nurse practices from a holistic framework and that recognizing a person within a context of "values is essential in providing a framework for planning, implementing, and evaluating outcomes" (AACN, 2008, p. 175).

The AHNA's Standards of Holistic Nursing Practice: Guidelines for Caring and Healing (Frisch et al., 2000) have specific standards for holistic nursing education focusing on nurse self-care, nursing theory as a foundation for practice, creating a healing health care environment, and care of the environment as essential to professional practice. Education-specific standards address maintaining current knowledge and competency in holistic practice, participation in continuing education, integration of multiple disciplines, development of holistic policies and guidelines, use of evidence-based practice, and certification as a means of advancing education (Frisch et al., 2000). This document's approach to education does not include exploration of students as holistic beings, power relationships in the classroom, or advocacy of social justice as experience for practice life. Frisch (2003) discusses the application of these standards and advocates for their inclusion throughout curricula or in an introductory course with additional concepts added where appropriate.

A different approach to holistic nursing in education includes holistic principles not just as content but as an approach to teaching content and developing a holistic learning environment. Although only a few articles have been written on this approach, it is an important step toward an EHNE. In a holistic pedagogy, courses are informal and incorporate multiple learning methods such as observation, hands-on, lived experience, and affective learning (Delaney, 2009; Leathard \& Cook, 2008; Yorks \& Sharoff, 2001). These courses focus on students as holistic learners, developing emotional awareness through reflection activities, and direct experiences with CAM. Assignments include traditional modes of aesthetic and existential learning such as journaling, case study, and integration of art, music, and poetry (Delaney, 2009; Yorks \& Sharoff, 2001). Authoritarian teacher-student power relationships are equalized through use of Peace and Power approaches, check-in, student-led seminars, and contracting for projects and grades (Chinn, 2001; Delaney, 2009; Leathard \& Cook, 2008; Yorks \& Sharoff, 2001).

Holistic pedagogy has been described as being supportive of students in general, but is discussed in the literature as a technique that is applied to a traditional course rather than as the driving philosophy of all classes in a program (Chinn, 2001; Delaney, 2009; Leathard \& Cook, 2008; Yorks \& Sharoff, 2001). It also does not establish as a goal in itself the care and development of students as holistic beings. Faculty using a holistic pedagogy model holism by integrating students' prior knowledge based on their clinical experiences but also including their cultural position, historical knowledge, and life experiences.

Emancipatory pedagogy is another approach to holism in nursing education. In contrast to a classroom environment that asks students to learn lectured content and regurgitate it on an exam (Romyn, 2000), a truly transformative education must incorporate the learner's prior knowledge, and learning must be cocreated with teachers, learners, and community (Freire, 1970, 1973). Emancipatory pedagogy requires a learning environment that acknowledges the importance of deeply contextualized meaning, of cocreating knowledge, and of developing ways of knowing through reflection on cultural/sociohistorical contexts (Chinn \& Kramer, 2004; 


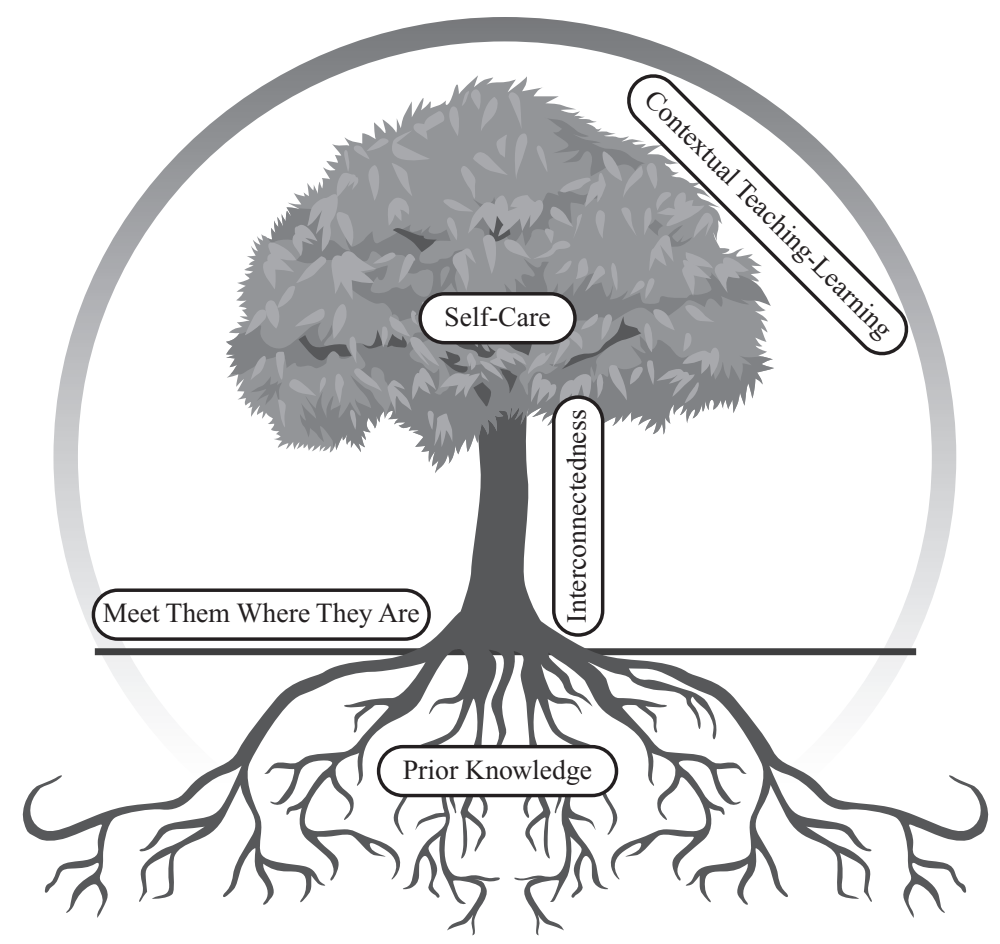

Figure 1. Model of midrange theory of Empowered Holistic Nursing Education.

Goodwin, Sener, \& Steiner, 2007; Romyn, 2000). Although these multidisciplinary pedagogies represent critical philosophies, EHNE is needed to unify them all to create a holistic nursing pedagogy.

\section{PRINCIPLES OF EHNE}

\section{Prior Knowledge}

Prior Knowledge means exploring the background, experiences, and perspectives of the learners. In Figure 1, Prior Knowledge is the roots and foundation of the tree. Learners are acknowledged as individuals and contribute their knowledge to the learning community of the classroom. Education scholars have found that Prior Knowledge is the realm from which learning proceeds; failure to acknowledge students' prior knowledge can prevent learning of new content (Dewey, 1997; Dixon-Krauss, 1996; Freire, 1970; Simmons et al., 1999; Stanley, 1996). It is also critical to recognize students' life experiences and cultural influences before meaningful learning can take place (Cross, 2003; Evans, Evans, \& Evans, 2001; Freire, 1970; Johnson, 1990; Solorzano, Miguel, \& Yosso, 2000; Tatum, 1997).

For example, African American students' experiences with racism have influenced their worldview of society, education, and health care. Historical experiences of discrimination at the hands of doctors and nurses cannot be ignored when considering patient resistance to medical care (Gamble, 1997; Klonoff \& Landrine, 1999; Stern, 2005). Therefore, combatting discrimination in the classroom is important in establishing an empowered and holistic environment. The EHNE educator must be aware of attempts to socialize students from nondominant groups into the culture of nursing, which is predominantly White, middle class, female, heterosexual, Christian, and able-bodied (Brown \& Marshall, 2008; Carnegie, 2005; Cross, 1996;

Prior Knowledge is the realm from which learning proceeds; failure to acknowledge students' prior knowledge can prevent learning of new content. 
France \& Fields, 2004; Johnson, 1990; Kelley \& Jones, 1994; Lipscomb, 1975; Love, 2009, 2010). Nurse educators must be aware of their own identity, privilege, and Prior Knowledge, and must question their expectations: How do I define professional behavior, and why? How is this content approached by individuals who are different from me?

Prior Knowledge includes all experiences that influence how learners integrate new knowledge. The EHNE educator is obligated to look well beyond the health care experiences and clinical experiences of learners. A nursing educator who is not conscious of his or her social privilege may not see how using certain analogies might marginalize students. A person who grew up in poverty in an inner city may not relate to the analogy that folding hospital corners is like folding a sail on a boat. Assessing students' prior knowledge at the beginning of class can determine where to begin presenting content. What do you know about heart disease? What have you heard on television or online? Do you know someone with heart disease? These are simple prompts to access learners' Prior Knowledge.

\section{Contextual Teaching-Learning}

Represented in Figure 1 as the arch, Contextual Teaching-Learning is the environment in which a learner is operating. This includes the learner's values, beliefs, worldview, and readiness to learn. In holistic nursing practice, the patient's readiness, level of comfort, emotional status, and social supports are assessed before teaching is begun (Kearney-Nunnery, 2008). For example, anxiety among nursing students is a well-researched topic; EHNE affords an opportunity to explore the source of this anxiety (see Table 1).

Access to resources is as important for students as it is for patients. For example, a nursing student who was frequently late, tired, and occasionally left early because she relied on buses for transportation to and from clinicals was viewed by her instructors as unprofessional. Challenging the power relationships in this scenario and learning from the student about her specific context may not fix the problem but would bring compassion and understanding to the situation and allow for support.

Addressing worldviews is an important aspect of context. A male student whose spiritual beliefs dictate particular rules for men and women may be unable to look at a teacher who frequently references her own body as an example during a health assessment course, preventing optimal learning. In Contextual TeachingLearning, the educator assesses students' views of healing and wellness, modeling

Interconnectedness reflects an ideal that people can share in the bond of humanity, regardless of the worldly barriers of politics, religion, or culture, in a universal reciprocity of love and responsibility. ways to reduce bias, discrimination, and culturally inappropriate care.

\section{Interconnectedness}

In Figure 1, Interconnectedness is represented by the tree trunk, which connects the earth, air, sky, water, and animals with one another. Interconnectedness is a foundational principle of holism and has been defined as

the idea that all people, animals, and the entire universe are connected in a powerful way. Its essential meaning reflects an ideal that people can share in the bond of humanity, regardless of the worldly barriers of politics, religion, or culture, in a universal reciprocity of love and responsibility. (Love, 2008, p. 255) 
Interconnectedness is often overlooked when holism is brought into a classroom. The teacher-student relationship has the opportunity for transcendence toward a rewarding relationship of growth and healing, just as in a nurse-patient relationship (Cumbie, 2001; Jackson, 2004; Leathard \& Cook, 2008; Watson, 2003, 2005).

Interconnectedness can be experienced directly in the classroom by both teachers and students (see Table 1). Creating learning communities where students use the safe space established by the teacher decreases barriers such as isolation and anxiety. These experiences have been found to be specifically poignant for students of color (Kosowski \& Grams, 2001; Love, 2010; McQueen, Shelton, \& Zimmerman, 2004). Interconnectedness is a philosophy of bringing together a class to learn from one another and to value differences by applying them toward a common goal. This can be done through reflective experiences, cocreating rules for classroom conduct, or creating a therapeutic communication structure for class. For example, expectations for safe communication can be stated in the syllabus. Use of problematic language containing stereotyping, ignorance, or bias is addressed publicly when it occurs to support the students in the class who may be oppressed by the comments. The speaker is stopped and simply asked, "Can you try that again?" giving an opportunity to correct the statement. Everyone is shown care and can safely learn from one another.

Interconnectedness in the classroom allows for modeling of therapeutic use of self, professional communication, and caring boundaries. In this author's experi-

ence, faculty often feel that connecting with students risks being taken advantage of or becoming too emotionally involved. Holistic nurses connect with patients in a way that fosters healing, establishes rapport, and leads to trust and caring (Cumbie, 2001; Jackson, 2004; Leathard \& Cook, 2008; Watson, 2006). EHNE is an empowered pedagogy that supports faculty connection with students to produce a healing classroom environment, a safe space, and a trusting relationship. Occasionally, a relationship with a patient violates the nurse's trust, but this does not prevent the holistic nurse from bringing his or her whole self to the next therapeutic context.

\section{Self-Care}

"We must learn to treat ourselves with love and respect before we are able to treat others that way" (Watson, 1998, p. 292). Self-Care is important to vulnerability, growth, and bringing an authentic and therapeutic self to holistic practice. In Figure 1, the leaves represent Self-Care in their ability to protect the tree from heat, to create food for the tree, and to direct water toward the center of the tree where it is needed most. Self-Care allows for CAM, classroom reflection on lived experiences, and meaning making (Riley, 2003). Nourishing the self allows nurse educators to sustain the energy needed to integrate EHNE and to allow the self to be renewed by that very practice. Achieving wellness for ourselves helps overcome self-doubt, resistance to change, and low self-esteem, and is necessary not only for holistic nurses but also must be modeled for students (Cowin \& Hengstberger-Sims, 2006; Gallob, 2003).

The nurse educator models Self-Care behaviors by living a holistic mind-set (Riley, 2003; Thornton, 2008; Tjale \& Bruce, 2007). Thornton (2008) stated that Self-Care is necessary if one is to be fully present to those one cares about. A nurse who feels depleted creates an unhealthy environment for patient care. The proper attitude brought to the classroom, as well as to the bedside, communicates safety and care (Thornton, 2008). Bringing CAM to the classroom in support of the students themselves can also model Self-Care. Leading progressive muscle relaxation, guided imagery, or breathing 
TABLE 1. The Five Principles of Empowered Holistic Nursing Education and Suggestions for Implementation

\begin{tabular}{|c|c|c|}
\hline Principle & Focus & Techniques of Implementation \\
\hline Prior Knowledge & $\begin{array}{l}\text { What knowledge } \\
\text { and experience } \\
\text { do students } \\
\text { bring? }\end{array}$ & $\begin{array}{l}\text { - Foster awareness of identity, privilege, } \\
\text { and assumptions of the teacher. } \\
\text { - Assess what students know about a topic } \\
\text { at the beginning of every class. } \\
\text { - Consider how the topic is approached by } \\
\text { different groups of people. }\end{array}$ \\
\hline $\begin{array}{l}\text { Contextual } \\
\text { Teaching-Learning }\end{array}$ & $\begin{array}{l}\text { What is the } \\
\text { student's } \\
\text { environment, } \\
\text { internal and } \\
\text { external, that } \\
\text { impacts ability } \\
\text { to learn? }\end{array}$ & $\begin{array}{l}\text { - Assess students' readiness to learn, } \\
\text { support system, and barriers to learning. } \\
\text { - Question students' contexts (e.g., cultural } \\
\text { perspective and learning needs). } \\
\text { - Address power structures in the } \\
\text { educational institution that reflect bias, } \\
\text { discrimination, or assumptions. }\end{array}$ \\
\hline Interconnectedness & $\begin{array}{l}\text { How can we } \\
\text { experience our } \\
\text { connection to } \\
\text { one another? }\end{array}$ & $\begin{array}{l}\text { - Model therapeutic use of self in } \\
\text { student-teacher interactions to foster } \\
\text { safe space and caring. } \\
\text { - Encourage students to learn from and } \\
\text { support one another. } \\
\text { - Cocreate rules for communication. }\end{array}$ \\
\hline Self-Care & $\begin{array}{l}\text { How do we } \\
\text { nurture } \\
\text { ourselves to be } \\
\text { able to nurture } \\
\text { others? }\end{array}$ & $\begin{array}{l}\text { - Teach CAM techniques to decrease stress } \\
\text { and anxiety and improve wellness. } \\
\text { - Incorporate self-care practices into the } \\
\text { teacher's personal life. } \\
\text { - Share self-care experiences with students. }\end{array}$ \\
\hline $\begin{array}{l}\text { Meet Them Where } \\
\text { They Are }\end{array}$ & $\begin{array}{l}\text { How is teaching } \\
\text { responsive to } \\
\text { the diverse } \\
\text { learning needs } \\
\text { of students? }\end{array}$ & $\begin{array}{l}\text { - Relate content to relevant real-life } \\
\text { examples by exploring power structures, } \\
\text { current events, and social justice. } \\
\text { - Focus teaching on where students' needs } \\
\text { are by integrating examples based on their } \\
\text { prior knowledge, culture, and experience. } \\
\text { - Acknowledge other events in the students' } \\
\text { lives that may need to be processed before } \\
\text { learning can continue. }\end{array}$ \\
\hline
\end{tabular}

Note. $\mathrm{CAM}=$ complementary and alternative modalities.

Achieving

wellness for

ourselves helps

overcome self-

doubt, resistance

to change, and

low self-esteem. techniques before exams shows students that the teacher recognizes their needs and is teaching them how to do Self-Care (see Table 1). This author has brought poetry about experiences at the bedside into class, providing a meaningful example of a Self-Care activity as well as a case study of an experience of end-of-life care.

\section{Meet Them Where They Are}

The concept of Meeting Them Where They Are is exemplified in Figure 1 by the ground at the base of the tree: the space in which the teacher can approach students, stand by them, and learn from them. This concept is an extension of the principle of Contextual 
Teaching-Learning. Once the learner's environment has been assessed and his or her worldview understood, then the nurse educator can begin to work with the student. Just as the patient is approached as a partner in care to determine what will be meaningful for him or her, the teacher needs to approach students as participants in their learning experience: integrating all learning styles, cultures, and learning needs and offering all students the opportunity to learn from one another and to feel supported in their learning experience. Meeting Students Where They Are means teaching based on what is relevant and meaningful to them, cocreating knowledge with them, and being adaptive and patient with the ebbs and flows of life (see Table 1).

Adapting content to make it meaningful to students is one of the keys to adult learning and critical learning. Students can learn about any topic by seeing a relevant application. How would public health nursing function with limited resources in the wake of a natural disaster? How does respiratory assessment for a coal miner relate to working conditions, politics, and access to care? How do cancer rates relate to environmental injustice and health disparities? Discussing power structures and oppression makes learning meaningful to students and helps develop a critical consciousness that empowers nurses as agents of change in patient advocacy and care.

Meeting Students Where They Are also means being aware of other experiences in their lives. When are their other projects and exams due? Where are they before coming to your class, and where will they go afterward? Are experiences shared after a recent event such as standardized nursing exams? After a student drops out of the program? After a holiday weekend, including those who observe other holidays than a traditional calendar? Incorporating what is going on in the lives of students allows the teacher to know when to push and when to take time for Self-Care. Just as a holistic nurse uses this awareness to help a patient process a new diagnosis before jumping in to ambulate, the EHNE principle of Meeting Them Where They Are helps the nurse educator navigate holism in the classroom.

\section{CONCLUSION}

EHNE applies the principles of holistic nursing practice to the classroom as student-centered learning. This midrange theory can be used to create an empowered holistic classroom environment in which students are cared for and nurtured as holistic beings. Creating this environment requires the nurse educator to do more than just teach CAM or focus on holism in patient care. EHNE creates an empowered classroom by modeling self-care and advocacy against bias and discrimination, and cocreating emancipatory knowledge. The care and development of the student is an end in itself, and is as important as preparing nurses to provide holistic care. Multicultural, ethical, holistic, and caring evidence-based practice all support EHNE as a nursing pedagogy.

\section{REFERENCES}

American Association of Colleges of Nursing. (2008). The essentials of baccalaureate education for professional nursing practice and tool kit. Retrieved from http:/ / www.aacn.nche.edu/

American Holistic Nurses Association. (1998). Description of holistic nursing. Flagstaff, AZ: Author. (Original work published 1992)

Bevis, E. (1988). New direction for a new age. In N. L. Nursing (Ed.), Curriculum revolution: A mandate for change (pp. 27-52). New York, NY: National League for Nursing Press. 
Bevis, E., \& Watson, J. (1989). Toward a caring curriculum: A new pedagogy for nursing. New York, NY: National League for Nursing Press.

Brown, J., \& Marshall, B. (2008). A historically Black university's baccalaureate enrollment and success tactics for registered nurses. Journal of Professional Nursing, 24(1), 21-29.

Bryne, M. (2001). Uncovering racial bias in nursing fundamentals textbooks. Nursing Healthcare Perspectives, 22(6), 299-303.

Carnegie, M. E. (2005). Educational preparation of Black nurses: A historical perspective. The Association of Black Nursing Faculty Journal, 16(1), 6-7.

Chinn, P. (2001). Peace and power. Boston, MA: National League for Nursing Press.

Chinn, P., \& Kramer, M. (2004). Integrated knowledge development in nursing (6th ed.). St Louis, MO: Mosby.

Cowin, L., \& Hengstberger-Sims, C. (2006). New graduate nurse self-concept and retention: A longitudinal survey. International Journal of Nursing Studies, 43(1), 59-70.

Cross, T. (1996). The state of African-Americans in nursing education. Journal of Blacks in Higher Education, 13, 51-55.

Cross, T. (2003). The racial shortfall in counselors for college-bound blacks. The Journal of Blacks in Higher Education, 39, 59-60.

Cumbie, S. (2001). The integration of mind-body-soul and the practice of humanistic nursing. Holistic Nursing Practice, 15(3), 56-62.

Darder, A. (1991). Culture and power in the classroom: A critical foundation for bicultural education. Westport, CT: Bergin \& Garvey.

Delaney, C. (2009). RN to BSN students' experiences in a holistic nursing course. Holistic Nursing Practice, 23(1), 39-48.

Dewey, J. (1997). Experience and education. New York, NY: Touchstone.

Dixon-Krauss, L. (1996). Vygotsky in the classroom. Mediated literacy instruction and assessment. New York, NY: Longman Publishers.

Evans, A. L., Evans, V., \& Evans, A. M. (2001). Historically Black colleges and universities. Education, 123(1), 2-18.

Finn, P. (1999). Literacy with an attitude: Educating working-class children in their own selfinterest. Albany, NY: State University of New York Press.

France, N., \& Fields, A. (2004). "You're just shoved into the corner": The lived experience of Black nursing students being isolated and discounted: A pilot study. Journal of Rogerian Nursing Science, 12(1), 28-36.

Freire, P. (1970). Pedagogy of the oppressed. New York, NY: Continuum.

Freire, P. (1973). Education for critical consciousness. New York, NY: Seabury.

Frisch, N. (2003). Standards of holistic nursing practice for quality undergraduate nursing curricula. Journal of Professional Nursing, 19(6), 382-386. http:/ / dx.doi.org/10.1016 /S8755-7223(03)00128-5

Frisch, N., Dossey, B. M., Guzzetta, C., \& Quinn, J. (2000). Standards of holistic nursing practice: Guidelines for caring and healing. American Holistic Nurses Association. Gaithersburg, MD: Aspen.

Gallob, R. (2003). Reiki: A supportive therapy in nursing practice and self-care of nurses. Journal of the New York State Nurses' Association, 34(1), 9-13.

Gamble, V. N. (1997). Under the shadow of Tuskegee: African Americans and health care. American Journal of Public Health, 87(11), 1773-1779.

Goodwin, M., Sener, I., \& Steiner, S. (2007). A novel theory of nursing education. Journal of Holistic Nursing, 25(4), 278-285.

Hooks, B. (1994). Teaching to transgress: Education as the practice of freedom. New York, NY: Routledge.

Jackson, C. (2004). Healing ourselves, healing others. Holistic Nursing Practice, 18(3), 127-141. Johnson, R. (1990). Survival skills needed by Black faculty and Black students. American Black Nurses Foundation Journal, 1(2), 24-26.

Kearney-Nunnery, R. (2008). Teaching-learning process. In Advancing your career: Concepts of professional nursing (4th ed., pp. 170-191). Philadelphia, PA: F.A. Davis. 
Kelley, J., \& Jones, G. (1994). Socializing culturally diverse students: A historically Black university's nursing education program. Journal of Cultural Diversity, 1(1), 8-13.

Klonoff, E., \& Landrine, H. (1999). Do Blacks believe that HIV/AIDS is a government conspiracy against them? Preventative Medicine, 28(5), 451-457.

Kolcaba, K. (2001). Evolution of the mid range theory of comfort for outcomes research. Nursing Outlook, 49(2), 86-92. http:/ /dx.doi.org/10.1067/mno.2001.110268

Kosowski, M., \& Grams, K. (2001). "They took the time ... they started to care": Stories of African American nursing students in intercultural caring groups. Advances in Nursing Science, 23(3), 11-27.

Leathard, H., \& Cook, M. (2008). Learning for holistic care: Addressing practical wisdom (phronesis) and the spiritual sphere. Journal of Advanced Nursing, 65(6), 1318-1327.

Leininger, M., \& McFarland, M. (2002). Transcultural nursing: Concepts, theories, research and practice (3rd ed.). New York, NY: McGraw Hill.

Lipscomb, L. (1975). Socialization factors in the development of Black childrens' racial self-esteem. Paper presented at the Annual Meeting of the American Sociological Association, San Francisco, CA.

Love, K. L. (2008). Interconnectedness in nursing: A concept analysis. Journal of Holistic Nursing, 26(4), 255-265.

Love, K. L. (2009). An emancipatory study with African-American nursing students at predominantly White nursing schools (Doctoral dissertation). Retrieved from ETD Collection for University of Connecticut. (Paper AAI3360697.)

Love, K. L. (2010). The lived experience of socialization among African American nursing students in a predominantly White University. Journal of Transcultural Nursing, 21(4), 342-350.

Marriner-Tomey, A., \& Alligood, M. R. (2006). Nursing theorists and their work (6th ed.). St. Louis, MO: Mosby Elsevier.

McQueen, L., Shelton, P., \& Zimmerman, L. (2004). A collective community approach to preparing nursing students for the NCLEX RN examination. Journal of the Association of Black Nursing Faculty, 15(3), 55-58.

Meleis, A. (2007). Theoretical nursing: Development and progress. New York, NY: Lippincott, Williams, \& Wilkins.

Meyer, C. (2003). How effectively are nursing educators preparing students to provide spiritual care? Nurse Educator, 28(4), 185-190.

Moccia, P. (1988). Curriculum Revolution: An agenda for change. In N. L. Nursing (Ed.), Curriculum Revolution: A mandate for change (pp. 108-121). New York, NY: National League for Nursing Press.

Randall, C., Tate, B., \& Lougheed, M. (2007). Emancipatory teaching-learning philosophy and practice education in acute care: Navigating tensions. Journal of Nursing Education, $46(2), 60-64$.

Riley, J. B. (2003). Holistic self care: Strategies for initiating a personal assessment. American Association of Occupational Health Nurses, 51(10), 439-448.

Romyn, D. (2000). Emancipatory pedagogy in nursing education: A dialectical analysis. Canadian Journal of Nursing Research, 32(2), 119-138.

Schrieber, R., \& Banister, E. (2002). Challenges of teaching in an emancipatory curriculum. Journal of Nursing Education, 41(1), 41-45.

Shor, I. (1992). Empowering education: Critical teaching for social change. Chicago, IL: University of Chicago Press.

Simmons, P. E., Emory, A., Carter, T., Coker, T., Finnegan, B., Crockett, D., . . L Labuda, K. (1999). Beginning teachers: Beliefs and classroom actions. Journal of Research in Science Teaching, 36(8), 930-954.

Solorzano, D., Miguel, C., \& Yosso, T. (2000). Critical race theory, racial microaggressions, and campus climate: The experiences of African American college students. The Journal of Negro Education, 69(1/2), 60-75.

Spence, D. (1994). The curriculum revolution: Can educational reform take place without a revolution in practice? Journal of Advanced Nursing, 19, 187-193. 
Stanley, N. (1996). Vygotsky and multicultural assessment and instruction. In L. DixonKrauss (Ed.), Vygotsky in the classroom: Mediating literacy instruction and assessment (pp. 133-148). New York, NY: Longman.

Stern, A. (2005). Sterilized in the name of public health: Race, immigration, and reproduction control in modern California. American Journal of Public Health, 95(7), 1128-1138.

Tarca, K. (2005). Colorblind in control: The risks of resisting difference amid demographic change. Educational Studies, 38(2), 99-120.

Tatum, B. D. (1997). "Why are all the Black kids sitting together in the cafeteria?": And other conversations about race. New York, NY: Basic Books.

Thornton, L. (2008). Holistic nursing: A way of being, a way of living, a way of practice! Imprint, 55(1), 32-39.

Tjale, A., \& Bruce, J. (2007). A concept analysis of holistic nursing care in paediatric nursing. Curationis, 30(4), 45-52.

Transcultural Nursing Society. (2010). Standards of practice for culturally competent nursing care executive summary. Transcultural Nursing Society, Expert Panel on Global Nursing and Health. Retrieved from http:/ / www.tcns.org/TCNStandardsofPractice.html

Van Niekerk, S. (1999). Leadership: A tool for empowerment in nursing education. Health SA Gesondheid, 4(2), 4-11.

Watson, J. (1998). Nightingale and the enduring legacy of Transpersonal Human Caring. Journal of Holistic Nursing, 16(2), 292-294. http:/ / dx.doi.org/10.1177/089801019801600218

Watson, J. (2003). Love and caring. Ethics of face and hand- an invitation to return to the heart and soul of nursing and our deep humanity. Nursing Administration Quarterly, 27(3), 197-202.

Watson, J. (2005). Caring Science as sacred science. Philadelphia, PA: F.A, Davis Company.

Watson, J. (2006). Caring theory as an ethical guide to administrative and clinical practices. Nursing Administration Quarterly, 30(1) , 48-55.

Yorks, L., \& Sharoff, L. (2001). An extended epistemology for fostering transformative learning in holistic nursing education and practice. Holistic Nursing Practice, 16(1), 21-29.

Correspondence regarding this article should be directed to Katie Love, PhD, APRN, BC, AHN-C, at kasha42@ gmail.com or http:/ / www.EHNE.webs.org 
Reproduced with permission of the copyright owner. Further reproduction prohibited without permission. 